\title{
Prospective evidence that HIV lipoatrophy and visceral adiposity are partially independent processes
}

This article was published in the following Dove Press journal:

Open Access Journal of Clinical Trials

21 January 2011

Number of times this article has been viewed

\author{
Handan Wand \\ Dianne Carey \\ Alexandra Calmy \\ Matthew Law \\ David Cooper \\ Sean Emery \\ Andrew Carr \\ National Centre in HIV Epidemiology \\ and Clinical Research, \\ University of New South Wales, \\ Sydney, NSW, Australia
}

Correspondence: Handan Wand National Centre in HIV Epidemiology and Clinical Research, University of New South Wales, Sydney, NSW 2052, Australia

Tel +6I 293850900

Fax +6I 293850910

Email hwand@nchecr.unsw.edu.au
Purpose: To investigate the patterns of change in objectively assessed body composition parameters and to determine to what extent the observed patterns correlate with modifiable variables and potential risk factors for lipodystrophy in human immunodeficiency virus (HIV)-infected lipoatrophic adults.

Method: Changes from baseline in limb fat and visceral adipose tissue (VAT), and their associations with antiretroviral therapy, body composition, and metabolic variables were investigated using linear and logistic regression models.

Results: Increases in limb fat were significantly associated with higher baseline limb fat $(P<0.0001)$, VAT $(P=0.023)$, and change from baseline to week 72 in VAT $(P<0.0001)$. On-study use of zidovudine or stavudine was negatively associated with a limb fat increase $(P=0.017)$. High baseline limb fat mass and VAT had negative effects on subsequent VAT increases at week 72 ( $P=0.016$ and $P=0.001$, respectively).

Conclusions: This large, prospective study in HIV-infected adults with moderate or severe lipoatrophy at baseline showed positive associations between changes in limb fat and VAT over 72 weeks. Risk factors for these two lipodystrophic features were different. Our findings suggest that lipoatrophy and fat accumulation are at least partially independent processes.

Keywords: HIV, lipoatrophy, lipohypertrophy, pathogenesis

\section{Introduction}

HIV lipodystrophy is a heterogeneous condition characterized by peripheral subcutaneous lipoatrophy of the limbs, face, and buttocks and/or accumulation of adipose tissue in the intra-abdominal space, dorsocervical region, and breasts (lipohypertrophy). ${ }^{1,2}$ Physical changes are commonly associated with metabolic alterations predominantly dyslipidemia and disorders of glucose homeostasis. ${ }^{1,2}$ It is unclear whether the central hypertrophy is secondary to peripheral lipoatrophy (an inability to store circulating triglycerides in subcutaneous fat), or is an effect of aging, recovery from human immunodeficiency virus (HIV) wasting, or a separate and direct effect of antiretroviral therapy on visceral fat which is biologically distinct from subcutaneous fat. ${ }^{3-5}$ Prospective evaluation of HIV lipodystrophy has demonstrated that limb fat, central abdominal fat, and lean mass increase over the first 24 weeks following antiretroviral therapy initiation. ${ }^{6}$ However, from week 24 onwards there is a selective, progressive loss of limb fat whilst visceral adipose tissue (VAT) remains relatively constant and significantly greater than at baseline. ${ }^{6}$

Cessation of the thymidine nucleoside reverse transcriptase inhibitors (tNRTIs), stavudine (d4T) and zidovudine (ZDV), improves peripheral lipoatrophy, but not submit your manuscript $\mid$ www.dovepress.com

Dovepress

DOI: $10.2147 /$ OJCT.SI 4359
Open Access Journal of Clinical Trials 201 I:3 I-7

(C) 20I I Wand et al, publisher and licensee Dove Medical Press Ltd. This is an Open Access article which permits unrestricted noncommercial use, provided the original work is properly cited. 
visceral fat. ${ }^{7,8}$ Treatments for visceral adiposity such as cessation of protease inhibitors, growth hormone, metformin, and growth hormone analogs have not been associated with improvements in lipoatrophy. ${ }^{9-12}$ Indeed, metformin and growth hormone reduce both fat compartments but, as both agents are lipolytic, this is not surprising. ${ }^{10,11}$ Nevertheless, it may be that clinical studies have been too short and/or patient numbers too small to determine whether lipoatrophy and central fat accumulation are related.

To investigate morphological abnormalities we evaluated long-term data from two randomized intervention lipoatrophy trials: MITOX (a switch from d4T or ZDV to abacavir for 24 weeks) ${ }^{13}$ and ROSEY (rosiglitazone or placebo). ${ }^{14}$ Earlier analyses of both studies had failed to determine any significant predictor of limb fat recovery apart from tNRTI cessation. Our main objective was to investigate the patterns of change in body composition parameters, limb fat mass, and VAT, and to examine to what extent the observed patterns correlate with modifiable variables as well as with potential risk factors for lipoatrophy and visceral adiposity.

\section{Methods}

\section{Participants}

A total of 214 participants from MITOX $(\mathrm{n}=106)$ and ROSEY $(n=108)$ were included. Both study populations have been described previously. ${ }^{13,14}$ Their main eligibility criteria were similar and included documented HIV-1 infection with moderate or severe peripheral lipoatrophy in at least one region (face, arms, legs, buttocks) on physical examination. MITOX was an open-label study in which lipoatrophic HIV-infected adults with suppressed viral replication were randomized to switch from ZDV $(n=26)$ or $\mathrm{d} 4 \mathrm{~T}(\mathrm{n}=78)$ to abacavir for 24 weeks. ${ }^{13}$ The switch was associated with a significant (0.4 kg [11\%]) improvement in limb fat and in subcutaneous thigh and abdominal fat mass over 24 weeks; the study continued with a further 72 weeks follow-up. ${ }^{7}$ ROSEY was a 48-week, double-blind study in which 108 lipoatrophic HIV-infected adults were randomly allocated to receive rosiglitazone $4 \mathrm{mg}(\mathrm{n}=53)$ or placebo twice daily $(\mathrm{n}=55) .{ }^{14}$ Participants had either received, or were currently receiving, ZDV or d4T therapy. After 48 weeks, all participants were offered open-label rosiglitazone for a further 48 weeks. However, the study was ceased after a mean 21 months of follow-up when the week 48 analysis showed rosiglitazone had no beneficial effect on limb fat, and although glycemic parameters improved, serum lipids were adversely affected.

\section{Assessments}

Body composition was quantified at baseline and then every 24 weeks. Total and regional body fat and lean tissue were measured by dual-energy X-ray absorptiometry (DEXA). VAT and subcutaneous abdominal tissue (SAT) were measured by computed tomography (CT) at the intervertebral space immediately below the L4 vertebra. ${ }^{15}$ Common protocols were used for DEXA and CT data acquisition and all scans were centrally analyzed at a single site by blinded technicians (one each for DEXA and CT scans).

Fasting total cholesterol, high-density lipoprotein (HDL) cholesterol, low-density lipoprotein (LDL) cholesterol, triglycerides, glucose, and insulin values were assessed at each time point as well as CD4 cell counts and plasma HIV RNA (lower limit of detection for screening 400 copies $/ \mathrm{mL}$; for analysis, 50 copies $/ \mathrm{mL}$ batch tested).

\section{Statistical analyses}

The primary outcome variables were change from baseline to week 72 in limb (arms plus legs) fat mass (assessed by DEXA) and change in VAT (assessed by CT). Combining participants from the two studies increased the statistical power to identify contributing factors for these outcome variables. All analyses were based on available data at study weeks included in the follow-up period and used a time window approach to present the results at baseline and at weeks 24, 48, and 72. Baseline participant characteristics were described using the median (25th and 75 th percentiles) and percentage for continuous and categorical variables, respectively.

Univariate and multivariate linear regressions were used to assess the relationships between potential predictors of limb fat and central obesity. Variables examined in univariate analysis included age, anthropometric (waist circumference, body mass index [BMI]), HIV-related measures (HIV disease stage, CD4+ cell count, plasma HIV RNA), baseline and on-study body composition parameters (limb fat mass, trunk fat, total body fat, lean body mass, VAT, SAT), and baseline and on-study lipid (total cholesterol, HDL cholesterol, LDL cholesterol, triglycerides) and glycemic (insulin, glucose) parameters. Variables associated with the use of antiretroviral therapy (nucleoside reverse transcriptase inhibitors [NRTIs], protease inhibitors, and $\geq 6$ months exposure to $\mathrm{d} 4 \mathrm{~T}$ or $\mathrm{ZDV}$ ) were included.

In multivariate analyses on-study lipid and glycemic values were excluded for ROSEY participants who received rosiglitazone, as rosiglitazone alters both insulin sensitivity 
and serum lipids. Multivariate models considered all variables with a $P$-value $\leq 0.1$ in initial analyses and used forward stepwise methods. All analyses were performed using STATA statistical software (version 10; Stata Corporation, College Station, TX).

\section{Results}

With the exception of viral load, baseline characteristics of the study groups were similar (Table 1). Although both studies had similar inclusion criteria, body composition parameters, limb fat mass and trunk fat, were slightly higher in MITOX participants compared to ROSEY participants (data not shown). The groups were similar in terms of current antiretroviral therapy and on-study tNRTI exposure. Overall, $99 \%$ of participants were male, $18 \%$ had AIDS, and $82 \%$ had an undetectable viral load ( $<50$ copies $/ \mathrm{mL}$ ). All participants were receiving antiretroviral therapy, $94 \%$ a NRTI backbone, $60 \%$ protease inhibitor/s, 55\% a nonnucleoside reverse transcriptase inhibitor, and $51 \%$ received either $\mathrm{d} 4 \mathrm{~T}$ or ZDV for at least 6 months during study follow-up.

Overall, waist circumference and BMI remained stable after week 24, whereas limb fat mass, trunk fat mass, and body fat mass showed an increasing trend over the 72-week follow-up period (Table 2). At 24 weeks, the median limb fat gain was $0.11 \mathrm{~kg}$, and this had increased to $0.33 \mathrm{~kg}$ at week 72 . In contrast, VAT decreased with median changes of $-3.17 \mathrm{~cm}^{2},-8.09 \mathrm{~cm}^{2}$, and $-8.13 \mathrm{~cm}^{2}$ at weeks 24,48 , and 72, respectively. Lipid parameters did not show consistent trend changes over time after exclusion of all ROSEY participants who had received rosiglitazone.

Changes in limb fat mass and VAT over 72 weeks were the primary outcome variables. Their associations with each other and possible predictive factors were investigated. In univariate analysis, the two variables were positively associated (Pearson correlation coefficient $=0.22, P=0.001$; Figure 1).

Univariate linear regressions were used to assess relationships between potential predictors of improved limb fat and VAT (Table 3). There was a significant inverse association between $\geq 6$ months on-study $\mathrm{d} 4 \mathrm{~T}$ or ZDV exposure and change in limb fat mass $(P=0.023)$. There was a negative association of marginal significance with protease inhibitor use at baseline and change in limb fat $(P=0.068)$. Baseline and on-study anthropometric and regional body fat parameters showed significant positive associations with limb fat mass change during follow-up. Baseline lean tissue mass showed a positive association with limb fat, while on-study lean tissue was inversely associated with a limb fat gain at week 72. Change in VAT was only significantly associated with on-study anthropometric and body composition parameters.

Multivariate analyses for the primary outcome variables are shown in Table 4. Increases in limb fat were significantly associated with higher baseline limb fat $(P<0.0001)$ and VAT $(P=0.023)$, and change in VAT from baseline to week $72(P<0.0001)$. At least 6 months on-study tNRTI exposure had a negative impact on subsequent limb fat mass gain $(P=0.017)$. VAT increases were significantly and negatively associated with baseline limb fat and baseline VAT $(P=0.016$ and $P=0.001$, respectively).

\section{Discussion}

We evaluated the association between peripheral and central fat using long-term data from two randomized intervention

Table I Baseline participant characteristics ${ }^{\mathrm{a}}$

\begin{tabular}{|c|c|c|c|}
\hline Parameter & $\begin{array}{l}\text { MITOX } \\
(n=106)\end{array}$ & $\begin{array}{l}\text { ROSEY } \\
(n=108)\end{array}$ & $\begin{array}{l}\text { Overall } \\
(n=2 \mid 4)\end{array}$ \\
\hline Gender (male) (\%) & 105 (99) & $106(98)$ & $211(99)$ \\
\hline Age (years) & $43(39-50)$ & $45(40-5 I)$ & $44(39-50)$ \\
\hline AIDS (category C disease), n (\%) & $19(18)$ & $19(18)$ & $38(18)$ \\
\hline CD4 cell count (cells $/ \mathrm{mm}^{3}$ ) & $579(390-702)$ & $577(371-720)$ & $576(390-705)$ \\
\hline HIV RNA < 50 copies/mL & $95(90)$ & $80(74)$ & $175(82)$ \\
\hline \multicolumn{4}{|l|}{ Current antiretroviral therapy } \\
\hline PI, n (\%) & $63(59)$ & $66(6 I)$ & $129(60)$ \\
\hline NRTI, n (\%) & $106(100)$ & $96(89)$ & $202(94)$ \\
\hline NNRTI, n (\%) & $56(53)$ & $62(57)$ & II 8 (55) \\
\hline On study d4T or ZDV ( $\geq 6$ months), n (\%) & $56(52)$ & $53(49)$ & $109(5 \mathrm{I})$ \\
\hline
\end{tabular}

Note: ${ }^{a}$ Numbers are median (25th and 75 th quartiles) unless otherwise indicated.

Abbreviations: $\mathrm{d} 4 \mathrm{~T}$, stavudine; NRTI, nucleoside reverse transcriptase inhibitor; NNRTI, non-nucleoside reverse transcriptase inhibitor; PI, protease inhibitor; ZDV, zidovudine. 
Table 2 Baseline and change during study weeks in anthropometric, body composition, lipid and glycemic parameters ${ }^{\mathrm{a}}$

\begin{tabular}{|c|c|c|c|c|}
\hline Parameter & $\begin{array}{l}\text { Baseline } \\
\text { (all data) }\end{array}$ & $\begin{array}{l}\text { Change at week } 24 \\
\text { (all data) }\end{array}$ & $\begin{array}{l}\text { Change at week } 48 \\
\text { (all data) }\end{array}$ & $\begin{array}{l}\text { Change at week } 72 \\
\text { (all data) }\end{array}$ \\
\hline \multicolumn{5}{|l|}{ Anthropometric measures } \\
\hline Waist circumference $(\mathrm{cm})$ & $87.00(81.00,92.00)$ & $0.00(-1.60,2.00)$ & $1.00(-2.00,2.50)$ & $1.00(-2.00,3.5)$ \\
\hline BMI $\left(\mathrm{kg} / \mathrm{m}^{2}\right)$ & $23.00(22.00,25.00)$ & $0.20(-0.30,0.70)$ & $0.30(-0.30,1.00)$ & $0.32(-0.30,1.00)$ \\
\hline \multicolumn{5}{|l|}{ Body composition } \\
\hline Limb fat mass $(\mathrm{kg})$ & $2.57(1.80,4.00)$ & $0.11(-0.11,0.46)$ & $0.16(-0.11,0.73)$ & $0.33(-0.04,1.12)$ \\
\hline Limb fat (\%) & $9.40(6.75,13.63)$ & $0.53(-0.38,1.84)$ & $1.00(-0.20,2.76)$ & $1.70(0.003,4.09)$ \\
\hline Trunk fat mass $(\mathrm{kg})$ & $7.31(5.24,9.84)$ & $0.37(-0.40,1.20)$ & $0.60(-0.20,1.50)$ & $0.77(-0.30,2.20)$ \\
\hline Body fat mass (kg) & $10.53(7.33,14.90)$ & $0.43(-0.44,1.65)$ & $0.96(-0.35,2.33)$ & $1.16(-0.36,3.00)$ \\
\hline Visceral adipose tissue $\left(\mathrm{cm}^{2}\right)$ & $111.45(80.00,163.00)$ & $-3.17(-27.12,15.44)$ & $-8.09(-29.00,8.00)$ & $-8.13(-32.00,15.85)$ \\
\hline $\begin{array}{l}\text { Lipid and glycemic } \\
\text { parameters }\end{array}$ & $\begin{array}{l}\text { Baseline } \\
\text { (all data) }\end{array}$ & Change at week $24^{b}$ & Change at week $48^{\mathrm{b}}$ & Change at week $72^{b}$ \\
\hline HDL cholesterol (mmol/L) & I. $10(0.90,1.40)$ & $0.00(-0.10,0.20)$ & $0.00(-0.10,0.10)$ & $0.00(-0.20,0.20)$ \\
\hline LDL cholesterol (mmol/L) & $3.30(2.60,3.90)$ & $0.20(-0.30,0.70)$ & $0.20(-0.30,0.70)$ & $0.15(-0.30,0.70)$ \\
\hline Triglycerides (mmol/L) & $2.40(1.60,3.70)$ & $0.10(-0.60,1.00)$ & $0.00(-0.70,0.80)$ & $0.20(-0.60,1.20)$ \\
\hline Insulin (mIU/L) & $8.30(5.30,12.85)$ & $0.40(-2.10,3.00)$ & $0.80(-2.09,4.30)$ & $0.40(-2.40,4.00)$ \\
\hline Glucose (mIU/L) & $5.00(4.60,5.40)$ & $0.00(-0.40,0.30)$ & $-0.10(-0.40,0.40)$ & $0.00(-0.60,0.60)$ \\
\hline
\end{tabular}

Notes: ${ }^{a}$ Numbers are median (25th and 75th quartiles) unless otherwise indicated; 'Data from rosiglitazone arm are excluded.

Abbreviations: BMI, body mass index; HDL, high-density lipoprotein; LDL, low-density lipoprotein.

trials that utilized objective body composition measures in HIV-infected lipoatrophic adults. Contrary to our hypothesis, we found a positive association between changes in limb fat and visceral fat over 72 weeks and different risk factors for improvement in these two physical features. Our analyses showed that over 72 weeks an improvement in limb fat was not associated with a reduction in visceral fat but rather an increase, and this positive correlation increased with longer follow-up.
Prospective evaluation of peripheral and visceral fat changes in HIV-infected adults has shown an increase in both limb and central abdominal fat over the first 24 weeks of antiretroviral therapy. ${ }^{6}$ These initial increases might suggest that similar factors drive the two phenomena. However, our study identified different risk factors for improvements in lipoatrophy and visceral adiposity thereby suggesting that peripheral fat loss and central fat accumulation are partially independent processes.

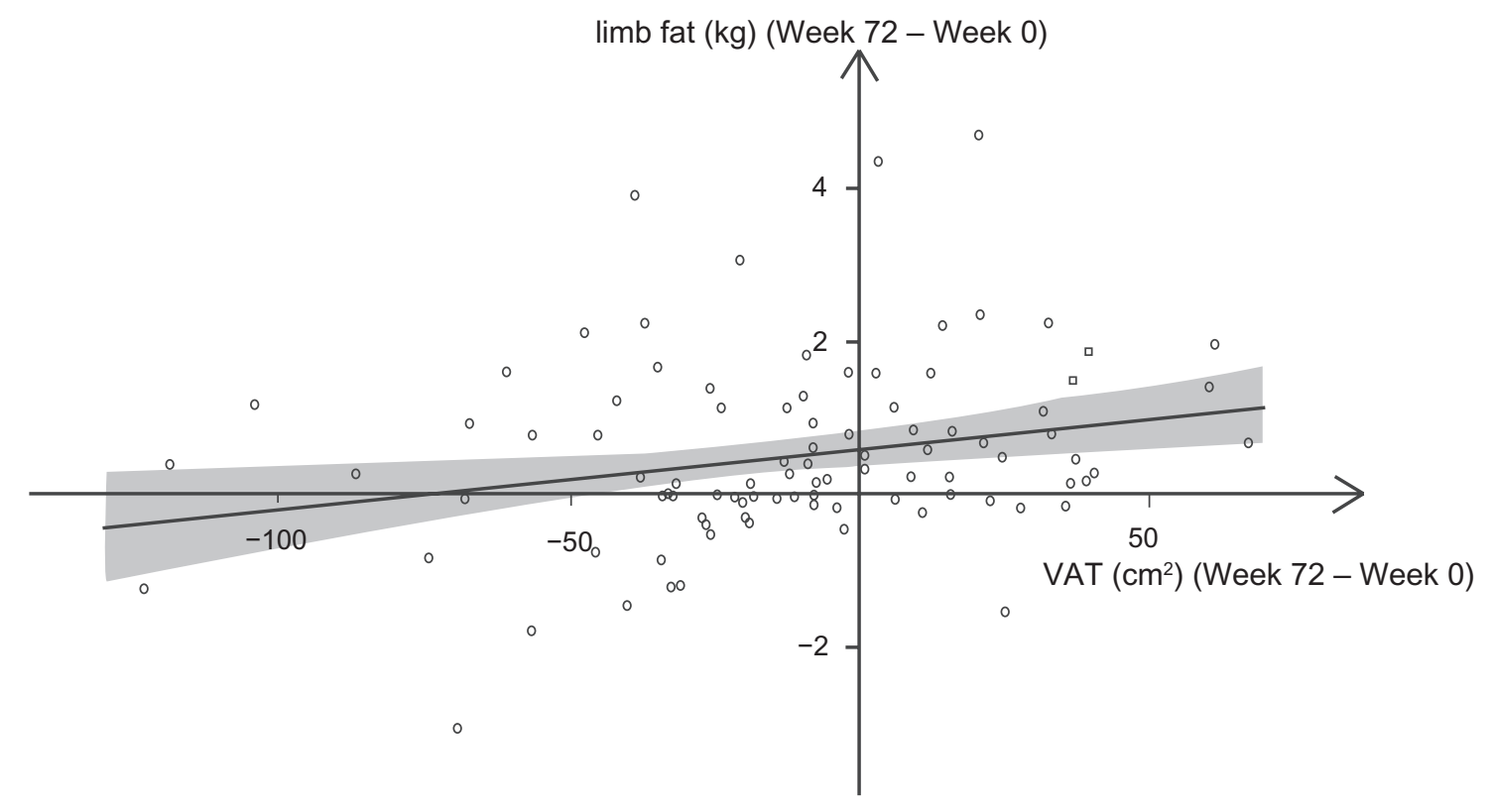

Figure I Association of limb fat and visceral adipose tissue (VAT) over 72 weeks. Note: Pearson correlation coefficient $=0.22(P=0.00 \mathrm{I})$ 
Table 3 Anthropometric and body composition parameters associated with change in limb fat and VAT between weeks 0 and $72^{\mathrm{a}}$ in univariate analysis

\begin{tabular}{|c|c|c|c|c|c|}
\hline \multirow[t]{2}{*}{ Parameter } & \multirow[t]{2}{*}{ Time } & \multicolumn{2}{|c|}{$\begin{array}{l}\text { Change in limb fat mass }(\mathrm{kg}) \\
\text { week } 72 \text {-week } 0\end{array}$} & \multicolumn{2}{|c|}{$\begin{array}{l}\text { Change in VAT }\left(\mathrm{cm}^{2}\right) \\
\text { week } 72 \text {-week } 0\end{array}$} \\
\hline & & Beta $(95 \% \mathrm{Cl})$ & $P$ & Beta $(95 \% \mathrm{Cl})$ & $P$ \\
\hline \multicolumn{6}{|l|}{ Antiretroviral therapy } \\
\hline On study d4T/ZDV & $\geq 6$ months & $-0.62(-1.15,-0.08)$ & 0.023 & $2.00(-15.91,11.92)$ & 0.78 \\
\hline Current PI & Baseline & $-0.51(-1.06,0.04)$ & 0.068 & $-5.18(19.33,9.00)$ & 0.47 \\
\hline \multicolumn{6}{|l|}{ Anthropometry } \\
\hline \multirow[t]{4}{*}{ BMI $\left(\mathrm{kg} / \mathrm{m}^{2}\right)$} & Baseline & $0.16(0.07,0.25)$ & $<0.0001$ & $-1.67(-3.93,0.60)$ & 0.15 \\
\hline & Change at week 24 & $0.34(0.02,0.67)$ & 0.039 & $8.87(0.82,16.91)$ & 0.031 \\
\hline & Change at week 48 & $0.29(0.03,0.55)$ & 0.027 & $7.58(0.90,14.22)$ & 0.027 \\
\hline & Change at week 72 & $0.40(0.13,0.67)$ & 0.004 & $7.21(0.48,13.94)$ & 0.036 \\
\hline \multirow[t]{4}{*}{ Waist circumference $(\mathrm{cm})$} & Baseline & $0.07(0.04,0.10)$ & $<0.0001$ & $-0.42(-1.15,0.31)$ & 0.25 \\
\hline & Change at week 24 & $-0.02(-0.10,0.06)$ & 0.69 & $0.61(-1.36,2.57)$ & 0.54 \\
\hline & Change at week 48 & $0.05(-0.03,0.13)$ & 0.21 & $1.26(-0.70,3.20)$ & 0.20 \\
\hline & Change at week 72 & $0.07(0.01,0.13)$ & 0.022 & $1.70(0.22,3.19)$ & 0.025 \\
\hline \multicolumn{6}{|l|}{ Body composition } \\
\hline \multirow[t]{4}{*}{ Limb fat mass (kg) } & Baseline & $0.38(0.28,0.49)$ & $<0.0001$ & $4.82(-0.90,10.54)$ & 0.098 \\
\hline & Change at week 24 & $1.07(0.84,2.30)$ & $<0.0001$ & $7.19(-3.92,18.31)$ & 0.20 \\
\hline & Change at week 48 & $0.62(0.40,0.84)$ & $<0.0001$ & $4.82(-0.90,10.54)$ & 0.098 \\
\hline & Change at week 72 & - & - & $6.95(2.98,10.92)$ & 0.001 \\
\hline \multirow[t]{4}{*}{ Limb fat percentage } & Baseline & $0.10(0.05,0.15)$ & $<0.0001$ & $-1.10(-2.37,0.17)$ & 0.089 \\
\hline & Change at week 24 & $0.35(0.27,0.42)$ & $<0.0001$ & $0.73(-3.08,4.54)$ & 0.71 \\
\hline & Change at week 48 & $0.37(0.27,0.46)$ & $<0.0001$ & $1.33(-1.54,4.21)$ & 0.36 \\
\hline & Change at week 72 & - & - & $1.70(-0.53,3.93)$ & 0.13 \\
\hline \multirow[t]{4}{*}{ Trunk fat mass (kg) } & Baseline & $0.15(0.09,0.21)$ & $<0.0001$ & $-1.24(-2.88,0.40)$ & 0.14 \\
\hline & Change at week 24 & $0.37(0.24,0.50)$ & $<0.0001$ & $5.58(-0.19,11.34)$ & 0.058 \\
\hline & Change at week 48 & $0.37(0.21,0.52)$ & $<0.0001$ & $6.01(1.77,10.26)$ & 0.01 \\
\hline & Change at week 72 & $0.39(0.28,0.5 \mathrm{I})$ & $<0.0001$ & $5.49(2.27,8.7 I)$ & 0.001 \\
\hline \multirow[t]{4}{*}{ Total body fat mass (kg) } & Baseline & $0.12(0.08,0.15)$ & $<0.0001$ & $-0.71(-1.78,0.36)$ & 0.19 \\
\hline & Change at week 24 & $0.3 \mathrm{I}(0.22,0.40)$ & $<0.0001$ & $3.82(-0.15,7.80)$ & 0.059 \\
\hline & Change at week 48 & $0.35(0.24,0.45)$ & $<0.0001$ & $4.43(1.47,7.39)$ & 0.004 \\
\hline & Change at week 72 & $0.29(0.22,0.37)$ & $<0.0001$ & $3.63(1.49,5.76)$ & 0.001 \\
\hline \multirow[t]{4}{*}{ Lean tissue mass (kg) } & Baseline & $0.06(0.02,0.09)$ & 0.002 & $-0.09(-1.02,0.84)$ & 0.85 \\
\hline & Change at week 24 & $-0.10(-0.20,0.009)$ & 0.07 & $1.12(-2.90,5.13)$ & 0.58 \\
\hline & Change at week 48 & $-0.10(-24,0.04)$ & 0.16 & $2.11(-1.64,5.87)$ & 0.27 \\
\hline & Change at week 72 & $-0.15(-0.28,-0.22)$ & 0.022 & $2.17(-1.18,5.52)$ & 0.20 \\
\hline \multirow[t]{4}{*}{$\operatorname{VAT}\left(\mathrm{cm}^{2}\right)$} & Baseline & $0.006(0.00 \mathrm{I}, 0.0 \mathrm{I})$ & 0.014 & $-0.14(-0.24,-0.04)$ & 0.008 \\
\hline & Change at week 24 & $-0.002(-0.01,0.005)$ & 0.60 & $0.43(0.25,0.60)$ & $<0.000$ I \\
\hline & Change at week 48 & $0.003(-0.007,0.01)$ & 0.56 & $0.66(0.48,0.84)$ & $<0.0001$ \\
\hline & Change at week 72 & $0.01(0.006,0.02)$ & 0.001 & $N / A$ & - \\
\hline \multirow[t]{4}{*}{ SAT $\left(\mathrm{cm}^{2}\right)$} & Baseline & $0.01(0.007,0.02)$ & $<0.0001$ & $-0.08(-0.18,0.03)$ & 0.16 \\
\hline & Change at week 24 & $0.03(0.02,0.04)$ & $<0.0001$ & $0.22(-0.10,0.54)$ & 0.17 \\
\hline & Change at week 48 & $0.03(0.01,0.04)$ & $<0.0001$ & $0.19(-0.07,0.46)$ & 0.15 \\
\hline & Change at week 72 & $0.01(0.005,0.02)$ & 0.0004 & $-0.03(-0.16,0.09)$ & 0.62 \\
\hline
\end{tabular}

Notes: ${ }^{\circ}$ On-study lipids and glycemic parameters excluded in rosiglitazone arm; Only variables with a $P$-value $\leq 0.1$ at least at one time point are included; Nonsignificant values at any time point on univariate analyses included: glucose, triglycerides, total cholesterol, high-density lipoprotein (HDL) cholesterol, low-density lipoprotein (LDL) cholesterol, insulin.

Abbreviations: BMI, body mass index; Cl, confidence interval; d4T, stavudine; PI, protease inhibitor; SAT, subcutaneous abdominal tissue; VAT, visceral adipose tissue; ZDV, zidovudine.

We found that exposure to $\mathrm{d} 4 \mathrm{~T}$ or ZDV for at least 6 months of study duration was associated with limb fat loss. Previous cross-sectional and prospective studies have demonstrated the association between tNRTI use and lipoatrophy, ${ }^{16}$ particularly d4T. ${ }^{6,17,18}$ Our findings are therefore in keeping with those of earlier studies.
This study does not demonstrate that peripheral lipoatrophy could result in visceral fat accumulation. However, it is clear that substantial fat accumulation is driven by other factors. For example in chronically infected individuals, numerous cell types other than those in blood are infected with HIV. These cells produce numerous proteins, enzymes, and 
Table 4 Multivariate analyses for change in limb fat and VAT between weeks 0 and $72^{\mathrm{a}}$

\begin{tabular}{|c|c|c|c|c|c|}
\hline \multirow[t]{2}{*}{ Parameter } & \multirow[t]{2}{*}{ Time } & \multicolumn{2}{|c|}{$\begin{array}{l}\text { Change in limb fat mass }(\mathrm{kg}) \\
\text { week } 72 \text {-week } 0\end{array}$} & \multicolumn{2}{|c|}{$\begin{array}{l}\text { Change in VAT }\left(\mathrm{cm}^{2}\right) \\
\text { week } 72 \text {-week } 0\end{array}$} \\
\hline & & Beta $(95 \% \mathrm{Cl})$ & $P$ & Beta $(95 \% \mathrm{Cl})$ & $P$ \\
\hline \multicolumn{6}{|c|}{ Antiretroviral therapy } \\
\hline On study d4T/ZDV & $\geq 6$ months & $-0.57(-1.03,-0.10)$ & 0.017 & - & - \\
\hline \multicolumn{6}{|l|}{ Body composition } \\
\hline Limb fat mass $(\mathrm{kg})$ & Baseline & $0.37(0.26,0.48)$ & $<0.0001$ & $-4.07(-7.34,-0.79)$ & 0.016 \\
\hline \multirow[t]{2}{*}{$\operatorname{VAT}\left(\mathrm{cm}^{2}\right)$} & Baseline & $0.004(0.00 \mathrm{I}, 0.0 \mathrm{I})$ & 0.023 & $-0.16(-0.25,-0.07)$ & 0.001 \\
\hline & Change at week 72 & $0.02(0.01,0.02)$ & $<0.0001$ & - & - \\
\hline
\end{tabular}

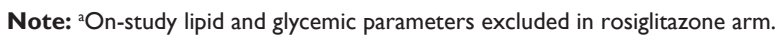

Abbreviations: $\mathrm{Cl}$, confidence interval; $\mathrm{d} 4 \mathrm{~T}$, stavudine; VAT, visceral adipose tissue; ZDV, zidovudine.

regulatory factors that can influence not only fat production but also its transport and storage. Another possibility is that accumulation of fat is merely an effect of aging.

This study identified different risk factors for peripheral and central fat improvement that may in part be explained by the significant differences in both fat composition and function. ${ }^{5}$ Visceral fat is composed predominantly of brown adipose tissue important for thermoregulation and heat production, while subcutaneous fat is white adipose tissue and its main function is storage of lipids for future energy needs. 5

There are limitations to this study. Most participants (99\%) were white men, reflecting the HIV epidemic in Australia. Therefore, the effect of gender cannot be evaluated. Furthermore, only patients with moderate or severe peripheral lipoatrophy were eligible for inclusion in MITOX and ROSEY, and so the extent to which our findings are able to be generalized to all HIV-infected lipodystrophic adults remains uncertain.

In summary, we showed in this large, prospective analysis a positive association between objectively assessed changes in limb and visceral fat over 72 weeks and identified different risk factors for their improvement, thereby suggesting they are partially independent processes. However, improvement in peripheral lipoatrophy could not be predicted and was incomplete. From a clinical perspective, our findings suggest that where alternative potent antiretroviral drugs are available, any agent known to induce lipoatrophy should be ceased as soon as possible. Additional studies to assess the mechanisms and consequences of our findings are required.

\section{Acknowledgments}

This publication was funded by the Australian Government Department of Health and Ageing. The views expressed in this publication do not necessarily represent the position of the Australian Government. The National Centre in HIV
Epidemiology and Clinical Research is affiliated with the Faculty of Medicine, The University of New South Wales, Sydney, Australia.

\section{Disclosure}

The authors declared no conflicts of interest in relation to this work.

\section{References}

1. Carr A, Miller J, Law M, Cooper DA. A syndrome of lipoatrophy, lactic acidaemia and liver dysfunction associated with HIV nucleoside analogue therapy: contribution to protease inhibitor-related lipodystrophy syndrome. AIDS. 2000;14:F25-F32.

2. Carr A, Samaras K, Thorisdottir A, Kaufmann GR, Chisholm DJ, Cooper DA. Diagnosis, prediction, and natural course of HIV-1 protease-inhibitor-associated lipodystrophy, hyperlipidaemia, and diabetes mellitus: a cohort study. Lancet. 1999;353:2093-2099.

3. Caron M, Auclair M, Vigouroux C, Glorian M, Forest C, Capeau J. The HIV protease inhibitor indinavir impairs sterol regulatory elementbinding protein-1 intranuclear localization, inhibits preadipocyte differentiation, and induces insulin resistance. Diabetes. 2001;50: 1378-1388.

4. Dowell P, Flexner C, Kwiterovich PO, Lane MD. Suppression of preadipocyte differentiation and promotion of adipocyte death by HIV protease inhibitors. J Biol Chem. 2000;275:41325-41332.

5. Klaus S. Functional differentiation of white and brown adipocytes. BioEssays. 1997;19:215-223.

6. Mallon PW, Miller J, Cooper DA, Carr A. Prospective evaluation of the effects of antiretroviral therapy on body composition in HIV-1-infected men starting therapy. AIDS. 2003;17:971-979.

7. Martin A, Smith DE, Carr A, et al. Reversibility of lipoatrophy in HIV-infected patients 2 years after switching from a thymidine analogue to abacavir: the MITOX Extension Study. AIDS. 2004;18: 1029-1036.

8. Moyle GJ, Sabin CA, Cartledge J, et al. A randomized comparative trial of tenofovir DF or abacavir as replacement for a thymidine analogue in persons with lipoatrophy. AIDS. 2006;20:2043-2050.

9. Carr A, Hudson J, Chuah J, et al. HIV protease inhibitor substitution in patients with lipodystrophy: a randomized, controlled, open-label, multicentre study. AIDS. 2001;15:1811-1822.

10. Kotler DP, Muurahainen N, Grunfeld C, et al. Effects of growth hormone on abnormal visceral adipose tissue accumulation and dyslipidemia in HIV-infected patients. J Acquir Immune Defic Syndr. 2004;35: 239-252.

11. Hadigan C, Corcoran C, Basgoz N, Davis B, Sax P, Grinspoon S. Metformin in the treatment of HIV lipodystrophy syndrome: a randomized controlled trial. JAMA. 2000;284:472-477. 
12. Koutkia P, Canavan B, Breu J, Torriani M, Kissko J, Grinspoon S. Growth hormone-releasing hormone in HIV-infected men with lipodystrophy: a randomized controlled trial. JAMA. 2004;292:210-218.

13. Carr A, Workman C, Smith DE, et al. Abacavir substitution for nucleoside analogs in patients with HIV lipoatrophy: a randomized trial. JAMA. 2002;288:207-215.

14. Carr A, Workman C, Carey D, et al. No effect of rosiglitazone for treatment of HIV-1 lipoatrophy: randomised, double-blind, placebo-controlled trial. Lancet. 2004;363:429-438.

15. Carr A, Emery S, Law M, et al. An objective case definition of lipodystrophy in HIV-infected adults: a case-control study. Lancet. 2003;361:726-735.
16. Saint-Marc T, Partisani M, Poizot-Martin I, et al. A syndrome of peripheral fat wasting (lipodystrophy) in patients receiving long-term nucleoside analogue therapy. AIDS. 1999;13:1659-1667.

17. Martin A, Smith D, Carr A, et al. Progression of lipodystrophy (LD) with continued thymidine analogue usage: long-term follow-up from a randomized clinical trial (the PIILR study). HIV Clin Trials. 2004; 5:192-200.

18. Miller J, Carr A, Emery S, et al. HIV lipodystrophy syndrome: prevalence, severity and correlates of risk in Australia. HIV Med. 2003; 4:293-301.

\section{Publish your work in this journal}

The Open Access Journal of Clinical Trials is an international, peerreviewed, open access journal publishing original research, reports, editorials, reviews and commentaries on all aspects of clinical trial design, management, legal, ethical and regulatory issues, case record form design, data collection, quality assurance and data auditing methodologies. The manuscript management system is completely online and includes a very quick and fair peer-review system, which is all easy to use. Visit http://www.dovepress.com/testimonials.php to read real quotes from published authors.

Submit your manuscript here: http://www.dovepress.com/open-access-journal-of-clinical-trials-journal 